\title{
EDUCAÇÃO PROFISSIONAL:
}

\section{Um Olhar Para o Que Dela Transborda}

Cristina Polimeni Góes ${ }^{1}$ Roberson Polimeni Góes ${ }^{2}$

\section{RESUMO}

O presente artigo objetiva apresentar a construção e a visão docente e empresarial da educação profissional brasileira, em âmbitos público e privado, tendo como campus de análise duas escolas públicas, de ensino profissionalizante, do Estado do Paraná e estudos realizados na clientela que procura formação profissional no Serviço Nacional de Aprendizagem Industrial(SENAI).Procuramos também fazer um paralelo entre a educação profissional ofertada pela Escola Tecnicista e a que hoje se vislumbra em nossa realidade, embasada pela pedagogia histórico-crítica e como os docentes que atuam frente a essa modalidade constroem e vislumbram o futuro da educação profissional no país.

Palavras-Chave: Educação Profissional. Perspectivas. Realidade.

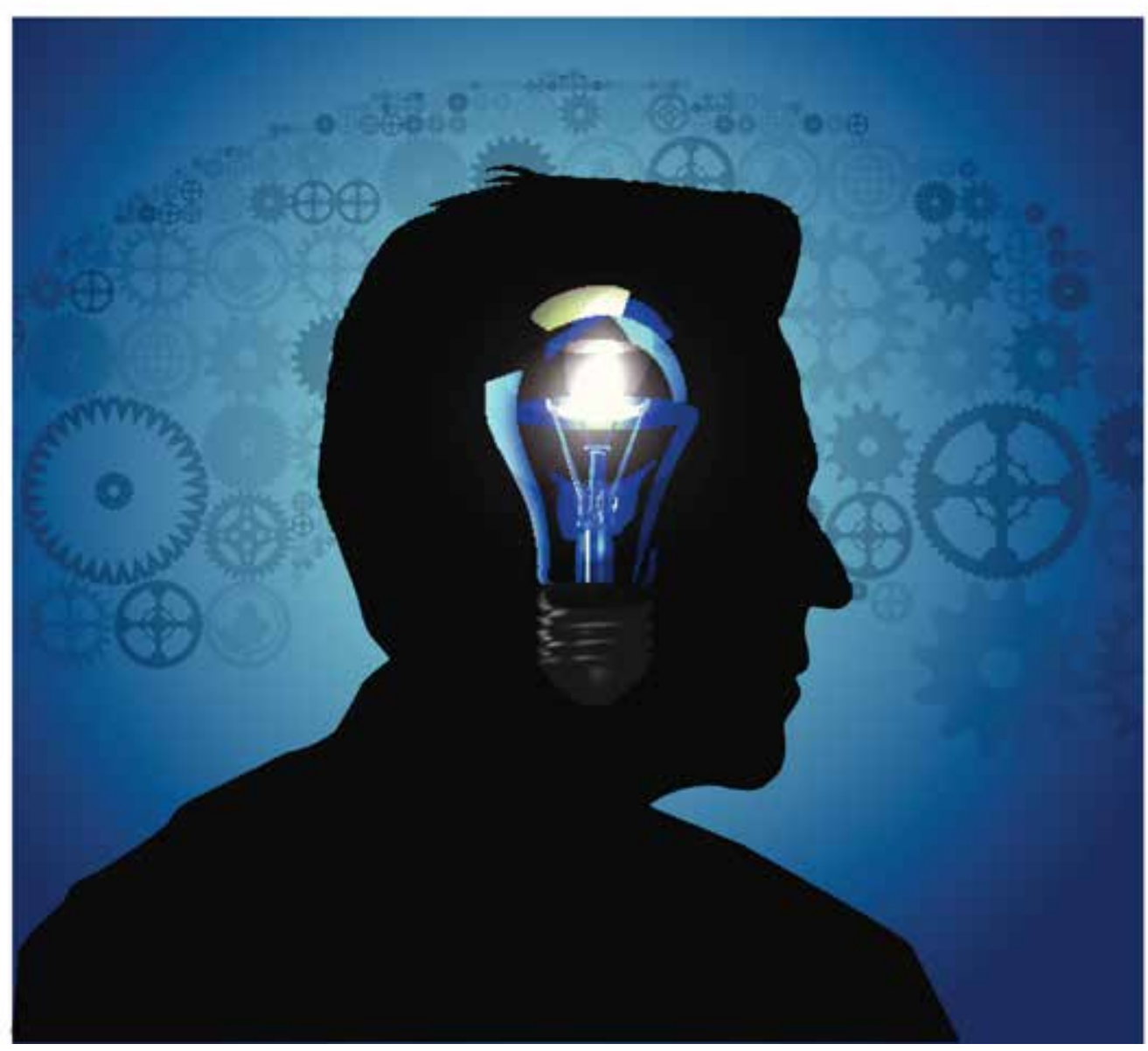




\section{INTRODUÇÃO}

A formação profissional de jovens e adultos tornou-se uma preocupação iminente em nosso país nos últimos anos, tanto para o Estado como para a iniciativa privada, pois se percebeu $o$ abismo que havia entre a oferta de postos de trabalho e a real e efetiva capacitação daqueles que se empenhavam em assumi-los.

Com o surgimento dessa inquietação, a escola surge como resposta ágil e versátil para a solução do ensino e aprendizagem dentro de cursos que possuem como objetivo final a formação de mão de obra qualificada para o mercado vigente.

Diante desse cenário, a reforma do ensino médio e do profissional objetiva adequá-los a uma nova realidade, na qual o domínio do conhecimento e a capacidade de competição são fatores fundamentais para a competitividade econômica de uma nação. Nesse sentido, a necessidade

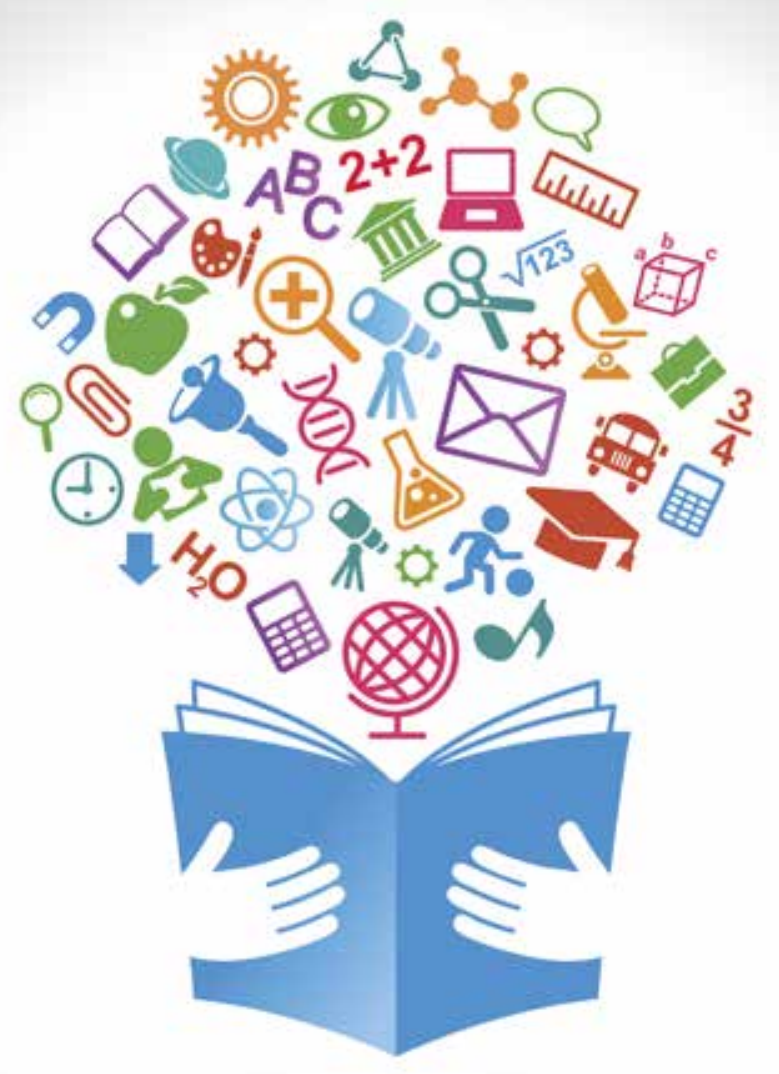

da educação contribuir para a constituição de um novo modelo de desenvolvimento sustentável é evidente, o que só pode ser possível estabelecendo-se mecanismos de aumento do nível de escolarização da população.

Pode-se observar que o Brasil vive um caos na educação do Ensino Médio, consequência de mais de uma década de políticas educacionais equivocadas. A herança dessa conturbada experiência são alunos filhos das correções de fluxo aplicadas nos anos 90, com o objetivo de diminuir a repetência para que os alunos estudassem na série considerada adequada para a idade. Ou seja, corrigiu-se o problema, mas sem medidas pedagógicas apropriadas, o que não privilegiou a construção do conhecimento.

Assim, para esses alunos, e não só para eles, mas para muitos outros que não veem mais expectativas novazio Ensino Médio, a melhor alternativa, praticamente a única projeção de futuro, são os cursos profissionalizantes, cursos técnicos ou outro tipo de formação voltada diretamente para o mercado trabalho. Tais opções representam, portanto, uma forma de integrar estudantes e sociedade em uma mesma perspectiva proativa, propiciando a esses indivíduos autoestima e saúde psicológica, advindas, também, da sua integração à sociedade produtiva.

\section{MAS UMA QUESTÃO NÃO QUER CALAR: COMO ESSES CURSOS ES- TÃO SE SAINDO DENTRO E FORA DOS MUROS DAS INSTITUIÇÕES QUE OS OFERTAM?}


os jovens e ouvidos muitos atentos às necessidades do mercado de trabalho são aspectos que devem ser considerados pelos tomadores de decisões na esfera da política educacional, uma vez que, enquanto quase $100 \%$ das crianças entre 7 e 14 anos estão na escola, apenas 40\% dos adolescentes estão cursando o Ensino Médio. Valorizar o ensino profissionalizante é, pois, valorizar um caminho rápido de integração dos jovens ao mercado de trabalho e à sociedade, mas será que isso está acontecendo?

\section{CURSOS PROFISSIONALIZANTES: UM ENSAIO NA LINHA DO TEMPO}

Faz-se iminente iniciar os estudos sobre os cursos profissionalizantes fazendo uma releitura de uma época em que o Brasil já percorrera o caminho da profissionalização por meio da educação.

Historicamente, precisa-se fazer mençãoà Escola Tecnicista. A pedagogia tecnicista aparece nos Estados Unidos na segunda metade do século XX e é introduzida no Brasil entre 1960 e 1970, onde proliferou o que Saviani,Lombardi e Sanfelice (1998) chamaram de "tecnicismo educacional", inspirado nas teorias behavioristas da aprendizagem e da abordagem sistêmica do ensino, buscando adequar a educação às exigências da sociedade industrial e tecnológica. Essa educação atua no aperfeiçoamento do sistema capitalista, que é a ordem social vigente, articulando-se diretamente com o sistema produtivo, cujo interesse é produzir indivíduos competentes para o mercado de trabalho, onde é valorizada, nessa perspectiva, a tecnologia.

A prática escolar nessa pedagogia tem como função especial adequar o sistema educacional com a proposta econômica e política do regime militar, preparando, dessa forma, mão de obra para ser aproveitada pelo mercado de trabalho. É nesse período que o espírito crítico e reflexivo é banido das escolas. Para essa tendência, o ensino é um processo de condicionamento por meio do uso do reforço das respostas que se quer obter, sendo o conteúdo as informações objetivas que podem proporcionar, ao fim do processo, a adequada adaptação do indivíduo ao trabalho.

Qual seria, nesse sentido, a diferença para a proposta dos cursos profissionalizantes na contemporaneidade?

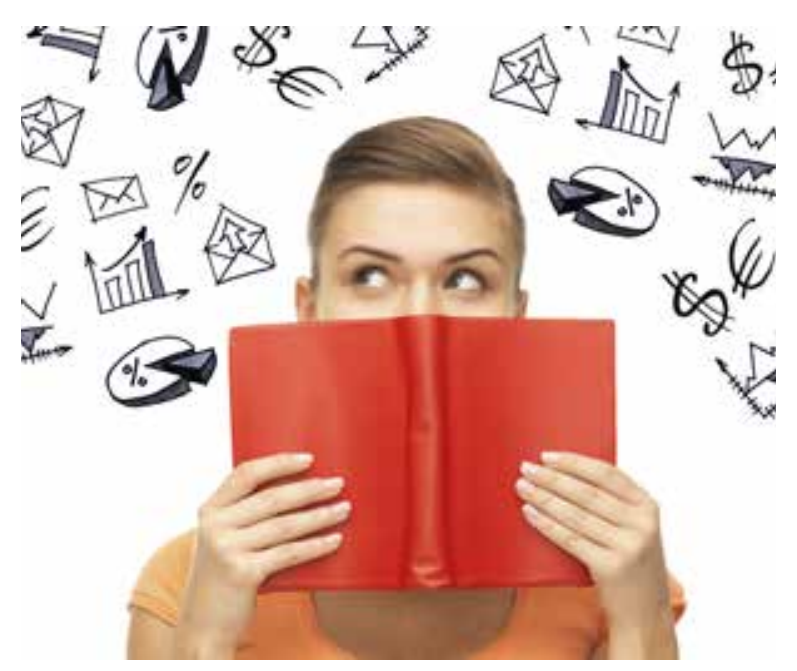

Esses cursos, atualmente, no Estado do Paraná, seguem como linha de atuação uma pedagogia histórico-crítica que, como se vê mais adiante, traz para a formação profissional o pensamento crítico e reflexivo sobre o papel de cada aluno e de cada profissional da educação no processo de trabalho. 
A partir de 2003, o Paraná CONCEBEU A EDUCAÇÃO PROfiSSIONAL COMO POLÍTICA PÚBLICA MATERIALIZADA NO Plano Estadual de Educação (SECRETARIA EstaduAL DE EDUCAÇÃO - SEED, 2004) E EM PROCESSO DE IMPLEMENTAÇÃO/ DESENVOLVIMENTO/CONSOLIDAÇÃO EM TODO O ESTADO, COMPROMISSADA COM A CONSTRUÇÃO E AVANÇO DA DEMOCRACIA SOCIAL, DE ACORDO COM OS TEXTOS ELABORADOS PELA SEED. ESSES SINTETIZARAM O PROJETO DE EDUCAÇÃO PROfiSSIONAL COMO UM PROCESSO PARA HUMANIZAR E SOCIALIZAR PARA A PARTICIPAÇÃO NA VIDA SOCIAL E, AO MESMO TEMPO, QUALIfICAR PARA O TRABALHO, MEDIADO PELA APROPRIAÇÃO E CONSTRUÇÃO DE CONHECIMENTOS CULTURAIS, CIENTÍfiCOS E TECNOLÓGICOS. O TRABALHO, COMO PRINCÍPIO EDUCATIVO NA SUA DIMENSÃO HISTÓRICO -ONTOLÓGICA, CONfIGUROU-SE, SOBRETUDO, COMO UM PRINCÍPIO ÉTICO-POLÍTICO (SEED, 2004).

Os cursos profissionalizantes passam a trazer em seu cerne a identidade de escola unitária, que é uma proposta de Gramsci de formação humana, tanto para as atividades intelectuais como para as instrumentais, sob as bases de uma cultura geral formativa de caráter teórico-prático. Segundo Gramsci (1968, p. 118), a escola de cultura geral deveria propor a tarefa de inserir os jovens na atividade social, depois de tê-los levado a certo grau de maturidade e capacidade, à criação intelectual e prática e a certa autonomia na orientação e na iniciativa.

Entende-se a educação profissional como uma esfera educacional complexa, síntese das inúmeras relações contraditórias entre trabalho, capital e educação, parte desta totalidade representa a perspectiva metodológica que reflete a concepção que os docentes possuem acerca da construção do conhecimento e das finalidades da educação profissional. Filosofia, didática e epistemologia integram-se neste momento. Segundo Rays (2006, p. 97), o método deve ser visto como "processo ordenado dialeticamente e uma integração, também dialética, entre pensamento, ação e reação”.

Os fundamentos políticos e pedagógicos para a educação profissional (SEED, 2005) concebem o processo de conhecimento ultrapassando a relação individual homem/conhecimento e incorporando as múltiplas relações do trabalho coletivo. $\mathrm{O}$ ato de conhecer, inicialmente teórico, parte do pensamento sobre a realidade e, ao passar à dimensão empírica estabelece a relação teoria/prática, que se consubstancia em um importante princípio metodológico.

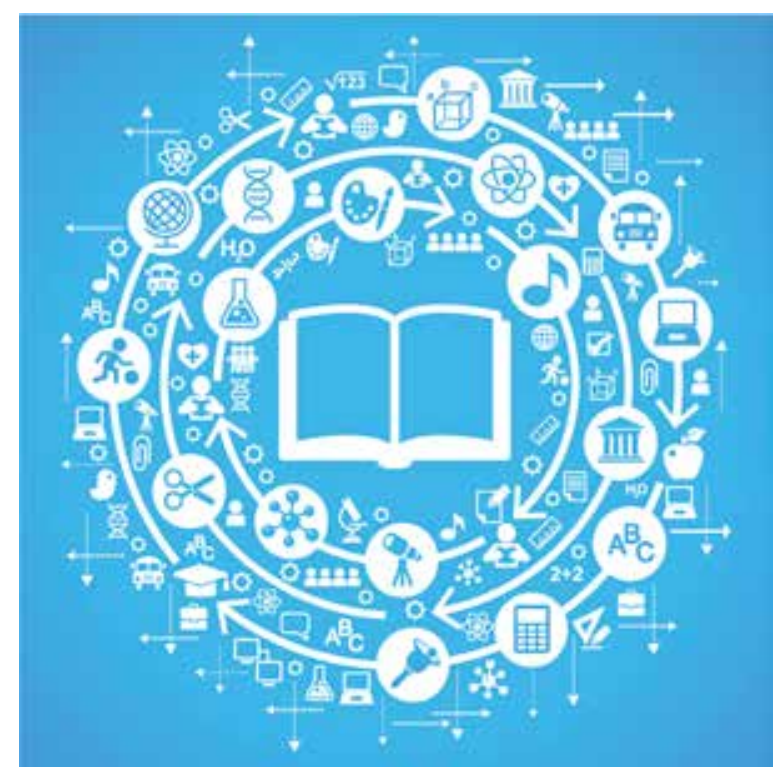


A relação parte/totalidade permite ao aluno o acesso a formas superiores de compreensão da realidade, pois para se conhecer uma totalidade é necessário relacioná-la à parte (os fatos) mediada pela história. Segundo Kuenzer (SEED, 2005, p.41) parte e totalidade, análise e síntese constituem-se em momentos entrelaçados do conhecimento. A dialética, como teoria do movimento da realidade, possui uma lógica concreta, baseada na prática-teoria-prática.

Nabusca de um caminho epistemológico, Marx formula com Engels, a partir das teses fundamentais do materialismo histórico, a compreensão da história a partir do desenvolvimento material, da determinação das condições materiais da existência humana. Segundo Marx (1986, p.40),

\section{Os homens são os produtores de suas representações, de suas ideias etc., mas os homens reais e ativos, tal como se acham condicionados por um determinado desenvolvimento de suas forças produtivas e pelo intercâmbio que a ele corresponde até chegar às suas formações mais amplas. A consci- ência jamais pôde ser outra do que o ser consciente, e o ser dos homens é o seu processo de vida real.}

É possível, até então, perceber que a educação profissionalizante tem como objetivo a formação integral do estudante, ou como diria Frigotto (2008, p.76):

\footnotetext{
O ensino médio, concebido como educação básica e articulado ao mundo do trabalho, da cultura e da ciência, constitui-se em direito social e subjetivo, portanto, vinculado a todas as esferas e dimensões da vida. Tratase de uma base para o entendimento crítico de como funciona e se constitui a sociedade humana em suas relações sociais e como funciona o mundo da natureza, da qual fazemos parte.
}

Nesse contexto, o pressuposto pedagógico que alinha o ensino médio com a ideia de uma organização curricular integrada tem o trabalho como princípio educativo. E vislumbrar o trabalho à luz desse pressuposto significa mais do que simplesmente atender ao mercado de trabalho, numa visão simplista e imediatista. Significa conceber a categoria trabalho como atividade humana, enquanto homem que toma a natureza, que dela se apropria e sobre ela constrói,desconstrói e reconstrói o seu entorno.

Segundo Kuenzer (1997, p. 26-27),

$$
\begin{aligned}
& \text { O saber é produzido no interior das } \\
& \text { relações sociais em seu conjunto: é } \\
& \text { uma produção coletiva dos homens } \\
& \text { em sua atividade real, enquanto } \\
& \text { produzem as condições necessárias } \\
& \text { à sua existência, através das relações } \\
& \text { que estabelecem com a natureza, com } \\
& \text { outros homens e consigo mesmo. O } \\
& \text { ponto de partida para a produção } \\
& \text { do conhecimento, portanto, são os } \\
& \text { homens em sua atividade prática, ou } \\
& \text { seja, em seu trabalho. }
\end{aligned}
$$

A retomada da oferta da Educação Profissional estava, de certa forma, consolidada e também foi assumida a oferta de cursos na forma subsequente, justificada pelo déficit de escolaridade técnica profissionalizante. Assim, a realidade da oferta dessa modalidade de ensino foi, e continuou sendo, até 2010, a da existência de propostas curriculares diferenciadas em sua estrutura e forma, mas unificadas pela mesma concepção educacional, tendo no trabalho como princípio educativo o seu ponto de convergência, de acordo com a política estabelecida nos dois períodos do governo Requião, de 2003 a 2010 (SEED, 2005). 
O documento Fundamentos Políticos e Pedagógicos

DA Educação Profissional

- SEED, PUBLICADO EM 2005,

TRAZ A CONCEPÇÃO ASSUMIDA,

DE REAfIRMAÇÃO DOS PRINCÍ-

PIOS CONSTANTES NO DECRETO

5.154/04, QUAIS SEJAM, O TRABA-

LHO, A CIÊNCIA, A TECNOLOGIA E

A CULTURA, BASE SOBRE A QUAL

O CONHECIMENTO E O CURRÍCULO

DEVERIAM ESTAR ANCORADOS, NA

PERSPECTIVA DE UMA EDUCAÇÃO

QUE TEM NO TRABALHO O SEU

PRINCÍPIO EDUCATIVO E NA FOR-

MAÇÃO POLITÉCNICA O HORIZON-

TE PARA A FORMAÇÃO UNILATERAL

DOS SUJEITOS, CONCEPÇÃO VÁLI-

DA PARA TODOS OS CURSOS PRO-

fiSSIONALIZANTES, INDEPENDENTE

DA FORMA DE SUA ORGANIZAÇÃO.

Seguindo essa linha de pensamento, o assumir o sentido da concepção na perspectiva da integração entre ensino e trabalho, tal como consta no documento base que expressa a sua política, significa assumir o que a $\operatorname{SEED~(2005,~}$ p.11) explicita:

[...] o compromisso com uma política de educação profissional em que o trabalho deve ser compreendido como princípio educativo no sentido da politécnica ou da educação tecnológica, sustentado pelos conceitos de trabalho, de cultura, de ciência e de tecnologia. O trabalho compreendido como fundamento unificador da educação como prática social; a ciência como disponibilizadora dos conhecimentos produzidos e legitimados socialmente e fundamento da técnica e da tecnologia; a cultura como categoria que sintetiza as diferentes formas de criação existentes na sociedade, através de seus símbolos, representações e significados... o princípio educativo do trabalho, aprofundado nesses fundamentos, considera o homem em sua totalidade histórica e, desta forma, a indissociabilidade entre trabalho manual e intelectual, levando em conta os limites e contradições daí decorrentes, os quais, com certeza, influenciam os processos de formação humana no e para o trabalho, num tempo e espaço determinados.

As dificuldades de avanço da unitariedade na educação no estado do Paraná estão sendo desvendadas à medida que se constata o percurso histórico dessas propostas e seus resultados. Por outro lado, a aproximação aos princípios da unitariedade e da politécnica tem sido conquistas históricas, permeadas por intervalos periódicos e capitaneadas a partir do campo político pedagógico, encontrando-se ainda a carência de estudos que possam melhor dimensionar a sua efetivação na prática escolar.

\subsection{Educação Profissional: um recorte docente}

O objetivo do estudo pretende realizar uma investigação qualitativa, ou seja, verificar em campo como a educação profissional é vivenciada pelos docentes que atuam junto aos cursos em escolas que possuem a sua oferta em suas grades curriculares.

Nesse sentido, foi realizada uma pesquisa com a participação de vinte professores, sendo de duas escolas públicas na região do município de Londrina, as quais ofertam cursos profissionalizantes, assim, verificaram-se as dificuldades e o retorno dos cursos por elas ofertados. 
A visão que esses profissionais têm da educação profissionalizante é dicotomizada: de um lado ainda prevalece a tendência de formação para o mercado de trabalho e a transmissão de conhecimentos práticos, contudo, por outro lado, é possível perceber que falam em formar o aluno para atender às demandas do mundo do trabalho, sem, contudo, oportunizar aos educandos suporte teórico e prático para que isso ocorra qualitativamente. Os entrevistados também valorizam questões como: saber pensar, construir atitudes, trabalhar a curiosidade, nortear a vida do aluno e trabalhar sua autossuficiência. Tais aspectos, além de extrapolarem o conceito de educação técnica, ainda ultrapassam a formação direcionada apenas para o mercado de trabalho, demonstrando que os professores também apresentam uma preocupação com uma formação mais ampla do aluno.

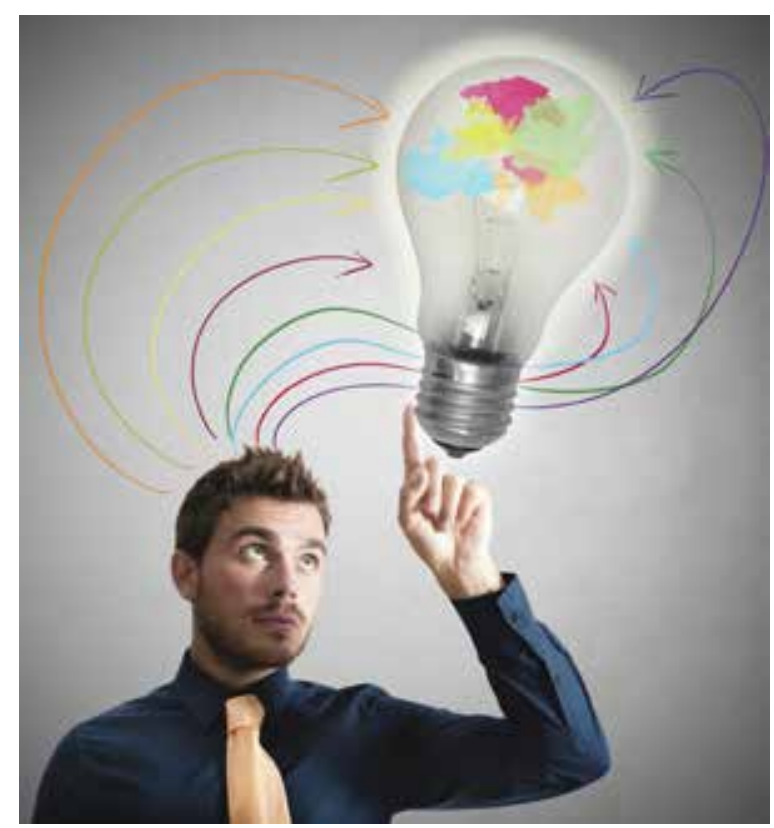

Quando questionados sobre o desempenho dos alunos, os professores se colocaram de forma bastante uniforme no que diz respeito às mudanças pelas quais os indivíduos passam na vida social, familiar, escolar e profissional. Todos concordam que essas mudanças vêm ocorrendo de forma desigual e muito rápida, trazendo um excesso de informações que causam nos indivíduos sentimentos de impotência, despreparo, urgência,insegurança e perplexidade. Por serem mudanças muito bruscas e aceleradas, não têm possibilitado tempo de assimilação para aceitação ou recusa desses novos valores impostos pela sociedade. Os professores entrevistados concordam também que tais mudanças afetam diretamente o desenvolvimento dos alunos durante o percurso escolar.

\section{OS ENTREVISTADOS ACREDI-}

TAM QUE AS REFORMULAÇÕES

TÊM UM CARÁTER POSITIVO,

AO DESVINCULAREM A EDUCA-

ÇÃO PROfiSSIONAL DO ENSINO

MÉDIO, OS ALUNOS TÊM GA-

RANTIDA UMA BASE DE FOR-

MAÇÃO GERAL, SÓLIDA, QUE

POSSIBILITA O EXERCÍCIO DA

CIDADANIA, DO PENSAMEN-

TO CRÍTICO. ABANDONA-SE O

PRINCÍPIO DE FORMAÇÃO QUE

TINHA COMO CONCEPÇÃO UMA

VISÃO TECNICISTA, UNICAMEN-

TE INSTRUMENTAL, PARA UMA

CONCEPÇÃO QUE VISA À FOR-

MAÇÃO INTEGRAL DO HOMEM,

CRIANDO-SE, fiNALMENTE, A

POSSIBILIDADE DE RELACIONAR

A CULTURA À PRODUÇÃO.

Já os professores que não acreditam nas reformulações defendem o fato de que dentro dessa nova organização curricular, o aluno, para obter a certificação técnica, precisa cursar o ensino médio e a educação profissional, de forma concomitante ou sequencial, levando mais tempo para se formar. Mas nem todos os alunos estão 
em condições financeiras que lhes permitam apenas estudar, muitos precisam colaborar com a renda familiar ou até sustentar suas famílias.

Há também alguns professores que se mantêm alheios à possibilidade ou não de mudanças.Eles consideram que um curso completa o outro, respondendo às atuais exigências:uma formação que garanta a flexibilidade profissional, menos específica e mais generalista.

\subsection{SENAI: desvelando o caminho da profissionalização}

De acordo com a pesquisa de Neri (2012), o número de brasileiros que frequentou cursos de educação profissional cresceu $83 \%$, entre maio de 2004 e setembro de 2010, revela estudo da Fundação Getúlio Vargas (FGV), em parceria com o Serviço Nacional de Aprendizagem Industrial(SENAI), divulgada em fevereiro de 2012 na Confederação Nacional da Indústria (CNI).

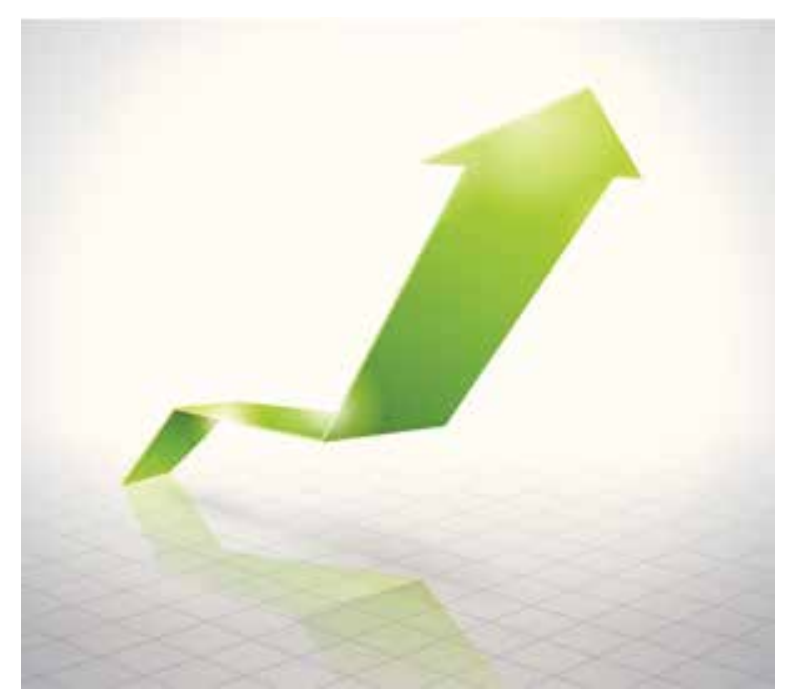

Os estudos mostram que os indivíduos oriundos da classe "C" são os que mais procuram pela formação profissional. A adesão da classe "C" aos cursos de educação profissional mostra que hoje o conhecimento é mais importante do que a compra de um carro e da adesão à TV a cabo. O estudo aponta que os jovens, entre 15 e 19 anos, dessa camada da população, fazem clara opção por carteira de trabalho e veem nesse tipo de formação uma alternativa de ascensão social, o que vem a ser um ponto altamente positivo no que se refere à formação de uma sociedade justa e igualitária, como preconiza a legislação nacional vigente.

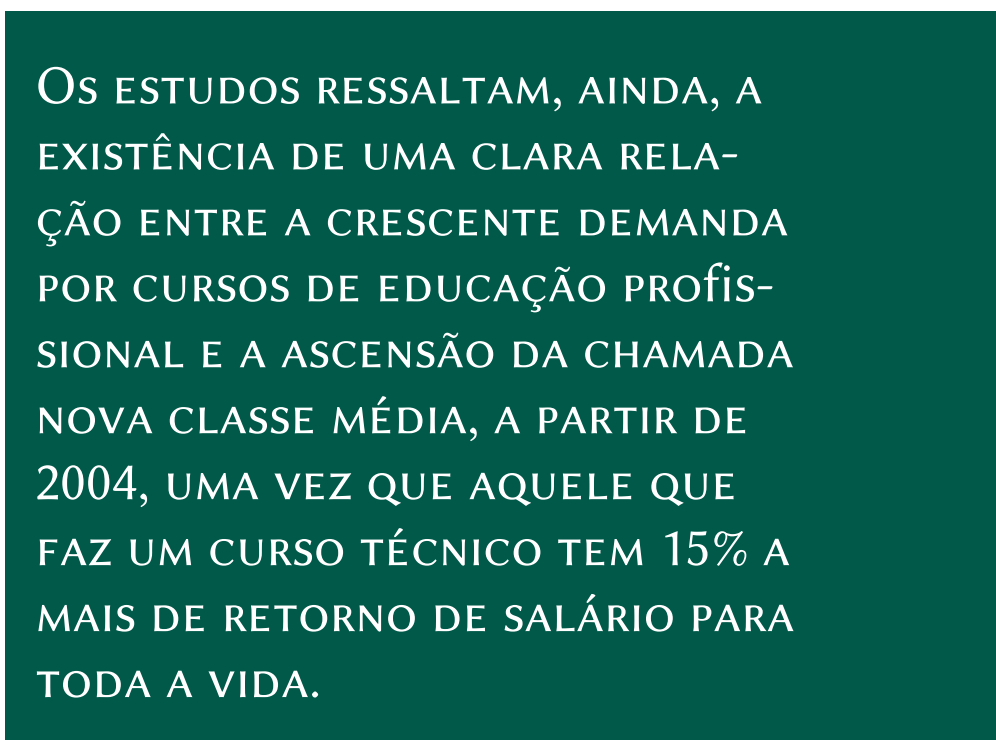

Contudo, nem tudo leva a um caminho repleto de sucesso na área da educação profissional também no setor privado. De acordo com estudos realizados pelo próprio SENAI, entre os que não frequentaram um curso de educação profissional, o que equivale a $77 \%$ da população, a grande maioria - 68,8\% - não o fez por desinteresse, o que revela que muito há por se trilhar na conscientização profissional dos brasileiros.

O Brasil passa por uma mudança cultural também no mundo do trabalho. E aumentar as oportunidades é fator crucial para o país crescer. Iniciativas como o Programa Nacional de Acesso ao Ensino Técnico e Emprego (PRONATEC) têm papel fundamental para fazer essa ponte 


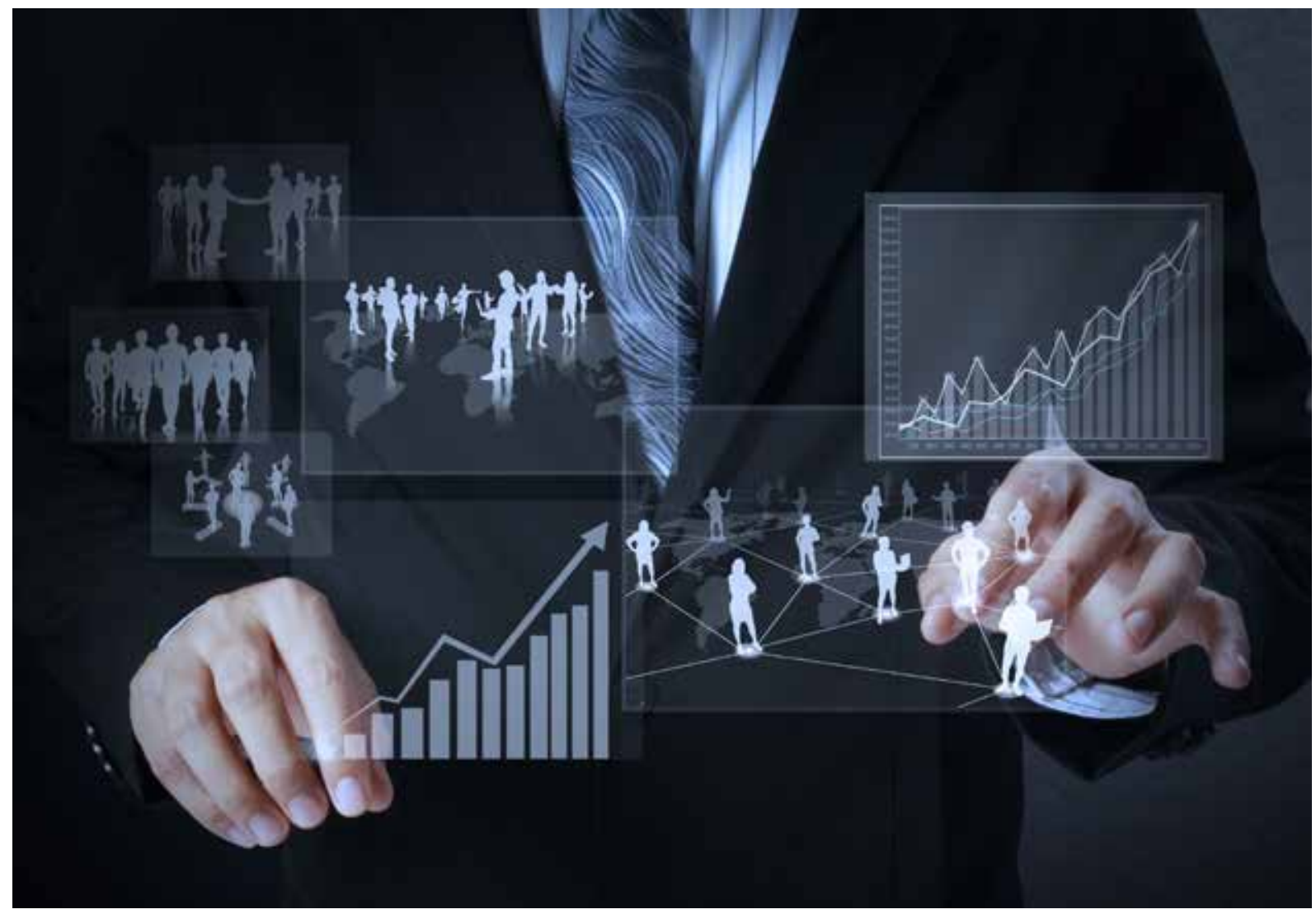

entre os alunos do ensino médio e os da educação profissional e estabelecer, nesse sentido, uma nova perspectiva profissional.

A pesquisa realizada por Neri (2012) mostra que entre2011 e 2015 a indústria brasileira investirá US $\$ 650$ bilhões, o que vai exigir um grande contingente de mão de obra qualificada, e que 90\% dos jovens que concluem o ensino médio não ingressam em curso de nível superior. Por isso, é iminente o incentivo de oportunidades e de informação a esses jovens sobre as diferentes formações técnicas - que não precisam de cursos de graduação.

O estudo revela também que alunos que frequentaram cursos de educação profissional dos níveis mais elevados têm mais possibilidade de encontrar trabalho na sua área de formação. Os Tecnólogos (nível superior) e os técnicos (nível médio) têm chances de 79,5\% e 70,1\%, respectivamente, de ingressar no mercado de trabalho na área de formação. Aqueles que frequentam cursos de curta duração-chamados de qualificação - têm chance média de 60,8\% de trabalhar no segmento para o qual se prepararam - ou seja, quase $10 \%$ de diferença em relação aos alunos dos cursos com maior nível de especialização. $\mathrm{O}$ estudo expõe ainda que os ex-alunos das três modalidades da educação profissional têm chances - entre 30,7\% e $50,8 \%$ - de conseguir uma colocação profissional em áreas diferentes da sua de formação. A possibilidade aumenta proporcionalmente à duração do curso.

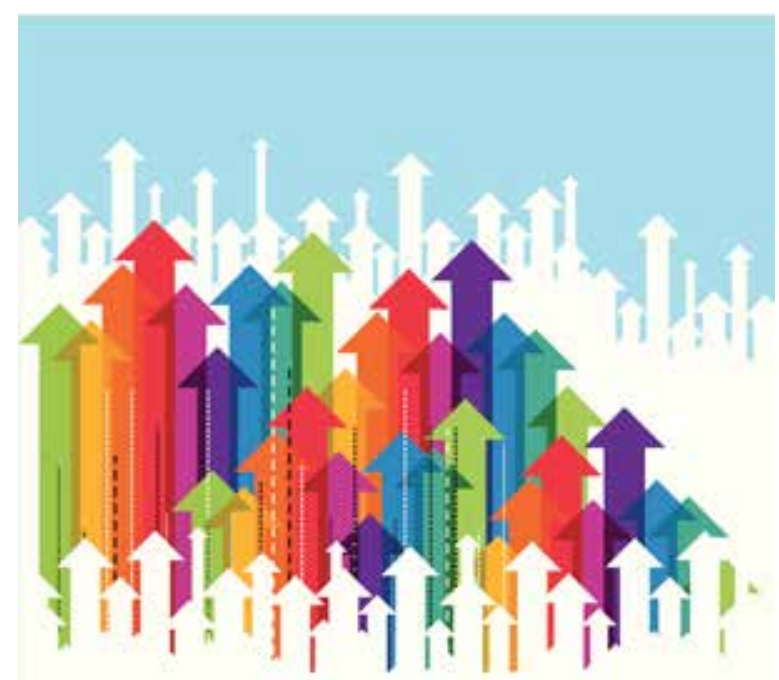


Diante de todo o exposto, é possível vislumbrar um futuro bastante promissor na educação profissional, desde que haja investimento qualitativo nos setores que fundamentam essa proposta de formação: qualificação dos professores, operacionalização dos cursos e acesso e permanência com qualidade daqueles que procuram por essa modalidade de ensino.

\section{CONSIDERAÇÕES FINAIS}

Ensinar é um processo complexo que exige mudanças significativas na realidade em que vivemos. Ensinar profissionalizando aqueles que estão sob nossos cuidados pedagógicos e instrumentais necessita de objetivos e metodologia bastante focada, pois estamos trabalhando com a formação de um indivíduo que fará uso dos conhecimentos adquiridos para o seu sustento e o dos seus. Nesse sentido, é preciso estar atentos a um futuro que é bastante imprevisível e diante do qual eles precisam estar preparados.

O processo de mudança na educação não é uniforme nem fácil. $\mathrm{Na}$ educação, muda-se aos poucos, em todos os níveis e modalidades educacionais. Há uma grande desigualdade econômica, de acesso, de maturidade, de motivação das pessoas. Alguns estão preparados para a mudança, outros não. É difícil mudar padrões adquiridos (gerenciais, atitudinais) das organizações, dos governos, dos profissionais e da sociedade.

Estamos vivendo uma etapa fascinante, na qual precisamos reorganizar tudo o que conhecíamos em novos moldes, formatos, propostas, desafios. A educação que formará o profissional do futuro será pautada em valores morais, em compromisso com a verdade, com o futuro das pessoas que fazem parte de uma organização. Ela será formada por hábitos novos, de amor, de ética, de integridade, de conhecimento real daquilo que se propõe fazer e de autoconhecimento, permitindo ao homem moderno renovar-se intimamente para o bem de toda uma sociedade. 


\section{PROFESSIONAL EDUCATION:}

\author{
A Look For What Spills From It
}

\section{ABSTRACT}

This article aims at presenting the construction and vision bothentrepreneurial and academic of Brazilian professional education in public and private spheres, considering, as reference, two schools of public vocational education in the state of Parana and studies performed among customers seeking training in the NationalIndustrialEducation (Senai). Wealsotried to draw a parallel between the professional education offered by the Technical oriented School and the one that today sees our reality grounded in the historicalcritical pedagogy and how teachers who act alongside this type of pedagogy construct and envision the future of vocational education in the country.

Keywords: Professional Education.

Perspectives. Reality.
BUENO, J. L. Rocha. A necessidade dos cursos profissionalizantes. Disponível em <http://blog. institutopadrereus.com/?p=11 >. Acesso em maio. 2012.

DUBAR, Claude. A socialização: construção das identidades sociais e profissionais. Porto: Porto Editora, 1997.

FRIGOTTO, G. Projeto Societário, Ensino Médio Integrado e Educação Profissional: o paradoxo da falta e sobra de jovens qualificados. In: PARANÁ. O Ensino Médio Integrado à Educação Profissional: concepções e construções a partir da implantação na rede pública estadual do Paraná. Curitiba, 2008.

GATTI, Bernadete. Os professores e suas identidades: o desvelamento da heterogeneidade. Cadernos de pesquisa, São Paulo, n. 98, p. 85-90, ago. 1996.

GRAMSCI, A. Os intelectuais e a organização da cultura. Rio de Janeiro: Civilização Brasileira, 1968.

KUENZER, A. Ensino de 2० Grau. O trabalho como Princípio Educativo. 3. ed. São Paulo: Cortez, 1997.

MARX, K. \& ENGELS, F. A ideologia alemã. São Paulo: Hucitec, 1986.

NERI, M.C. As razões da educação profissional: olhar da demanda. Disponível em http://www.cps.fgv. br/cps/bd/senai_razoes/.Acesso em maio. 2012.

NÓVOA, António. Os professores e as histórias da sua vida. In: NÓVOA, António (Org.). Vidas de professores. Porto: Porto Editora, 1992. 


\section{SOBRE OS AUTORES}

OLIVEIRA, Maria Rita N. S. Mudanças no mundo do trabalho: acertos e desacertos na proposta curricular para o ensino médio (Resolução CNE 03/98). Diferenças entre formação técnica e formação tecnológica. Educação e Sociedade, Campinas, n. 70, p. 40-62, abr. 2000.

PARANÁ, Secretaria de Estado da Educação. Plano Estadual de Educação: uma construção coletiva. Estudos temáticos para o PEE - PR. Doc. 2 (Versão preliminar), 2004.

PARANÁ, Secretaria de Estado da Educação. Educação Profissional na Rede Pública Estadual: Fundamentos Políticos e Pedagógicos (Versão preliminar), 2005.

RAYS, O. A. Metodologia do ensino: cultura do caminho contextualizado. In: Veiga, I. P. A.(Coord.). Repensando a didática. 23a ed. Campinas: São Paulo: Papirus, 2006.

SAVIANI, Dermeval; LOMBARDI, José Claudinei; SANFELICE, José Luis. História e história da educação: $\mathrm{O}$ debate teórico-metodológico atual. 1aed: São Paulo: Autores associados, 1998.

Data de recebimento: 27/04/13

Data de aprovação: 18/11/13

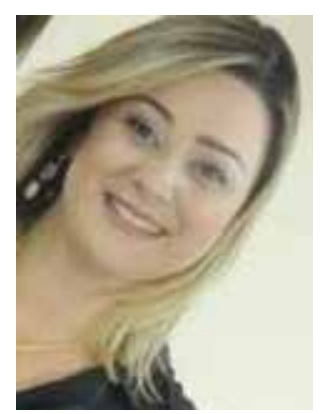

Cristina Polimeni Góes

Professora de Língua

Portuguesa, graduada pela

Universidade Estadual de Londrina (UEL), pedagoga graduada pela Universidade Luterana do Brasil, especialista em

Educação Especial e em Gramática Aplicada ao Texto. É professora PDE, em nível de mestrado, em Análise do Discurso de linha francesa, pela Universidade Estadual de Londrina (UEL), em parceria com a Secretaria Estadual de Educação do Paraná. É professora da Educação Básica da Secretaria Estadual de Educação do Estado do Paraná. Coordenou a implantação de cursos profissionalizantes no Colégio Estadual Olavo Bilac - EFMNP, no município de Cambé, estado do Paraná, onde atuou, posteriormente, como coordenadora desses cursos.

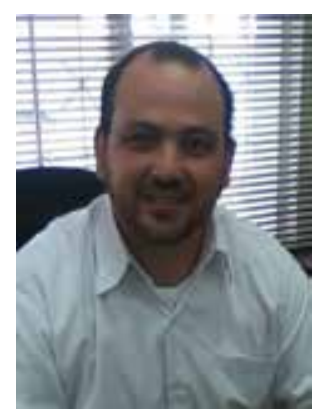

\section{Roberson Polimeni Góes}

Graduado em Tecnologia Mecânica (UTFPR) e em Pedagogia para Formadores em Educação Profissional (UNISUL), Mestre em Engenharia Mecânica (UERJ), MBA em Gestão Industrial (SENAI/ $\mathrm{SC}$ ), MBA em Consultoria Empresarial (SENAI/ SC), Técnico Mecânico (CEFET/PR). Docente no programa de Pós- Graduação nos cursos Engenharia de Manutenção Industrial (SENAI/ $\mathrm{SC}), \mathrm{MBA}$ Gestão Industrial (SENAI-SC) e em Lean Manufacturing (SENAI/SC). No SENAI/ $\mathrm{PR}$ atua como consultor técnico e instrutor nas áreas ligadas a Metal Mecânico: implantação de 
manutenção preventiva, TPM, PCM, layout, me-

lhoria de processos (solda, usinagem, estampagem, conformação mecânica, caldeiraria, serralheria, automação), inspetor de solda para qualificação de procedimentos e soldadores, como docente nos cursos técnico-tecnológicos, atua nas modalidades de: metrologia, elementos de máquinas, resistência dos materiais, desenho técnico, manutenção industrial, projetos, pneumática e hidráulica.

$* * *$

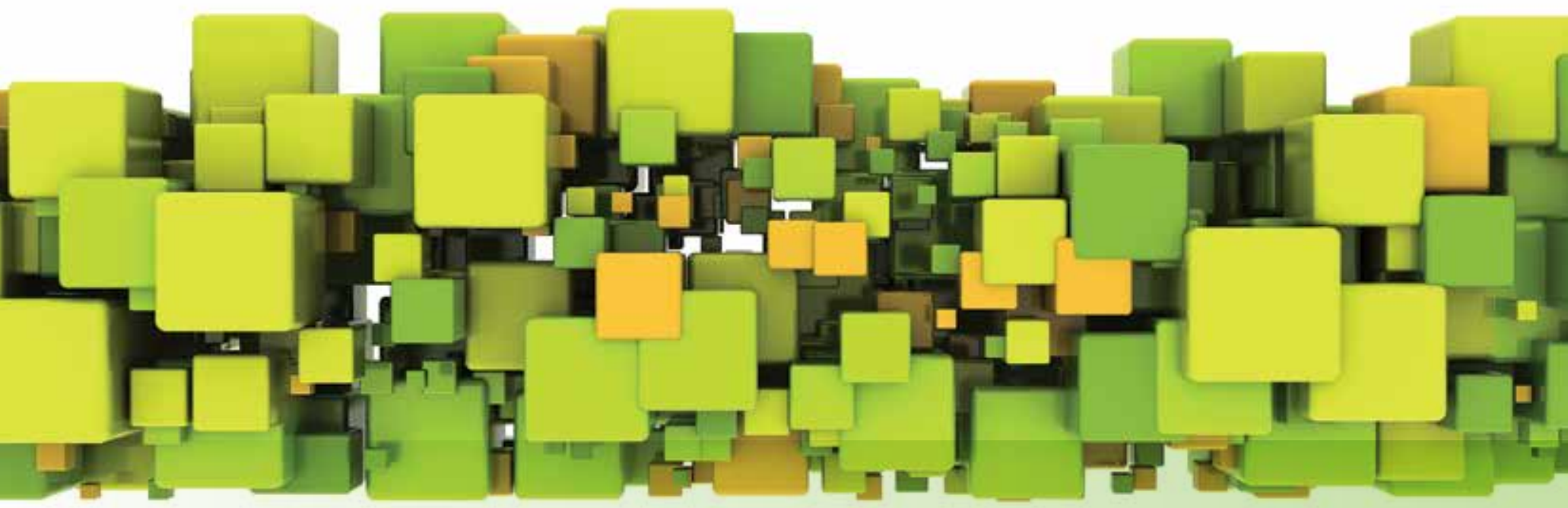

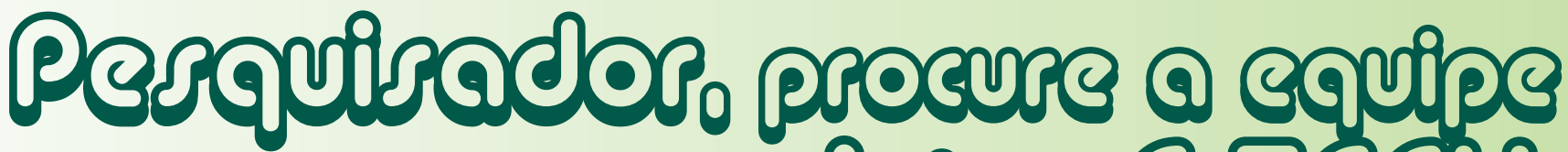 SCHOOHAO SA RSVISEA BOTESH

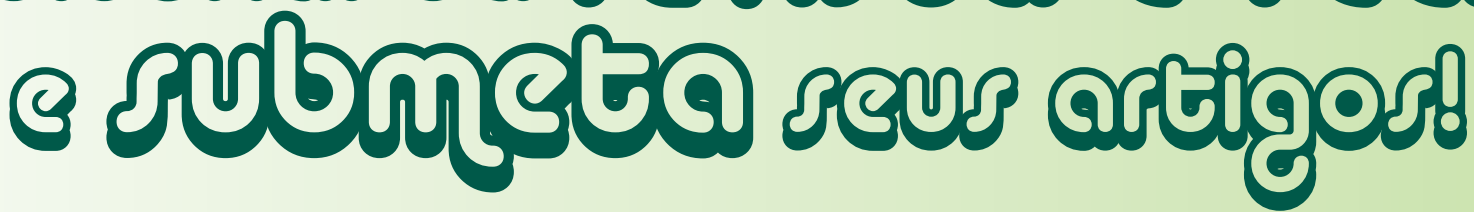

Revista E-TECH. Tecnologia para Competitividade Industrial.

FiesC. Federação da Industria do Estado de Santa Catarina. A Força da Indústria Catarinense.

SENAI. Serviço Nacional de Aprendizagem Industrial. Uma Iniciativa da FIESC 